\title{
In vitro treatment of congenital disorder of glycosylation type Ia using PLGA nanoparticles loaded with GDP-Man
}

\author{
BARBARA BORTOT ${ }^{1}$, ELEONORA DE MARTINO ${ }^{2}$, ALESSANDRA TESSER $^{1}$, BLENDI URA $^{1}$,

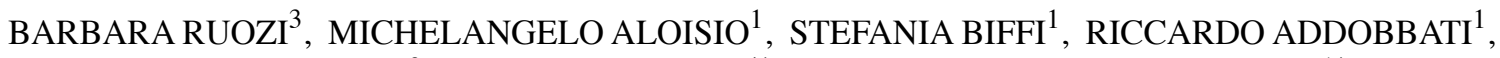 \\ GIOVANNI TOSI $^{3}$, DIEGO DOLCETTA ${ }^{4 *}$ and GIOVANNI MARIA SEVERINI ${ }^{*}$ \\ ${ }^{1}$ Institute for Maternal and Child Health-IRCCS ‘Burlo Garofolo', I-34137 Trieste; ${ }^{2}$ DSM, Department of Medical Sciences, \\ University of Trieste, I-34149 Trieste; ${ }^{3}$ Department of Life Sciences, University of Modena and Reggio Emilia, \\ I-41121 Modena; ${ }^{4}$ UOSD SAFU, RiDAIT Department, The Regina Elena National Cancer Institute, I-00144 Rome, Italy
}

Received July 16, 2018; Accepted January 29, 2019

DOI: $10.3892 / \mathrm{ijmm} .2019 .4199$

\begin{abstract}
Congenital disorder of glycosylation (CDG) type Ia is a multisystem disorder that occurs due to mutations in the phosphomannomutase 2 (PMM2) gene, which encodes for an enzyme involved in the $\mathrm{N}$-glycosylation pathway. Mutated PMM2 leads to the reduced conversion of mannose-6-P to mannose-1-P, which results in low concentration levels of guanosine 5'-diphospho-D-mannose (GDP-Man), a nucleotide-activated sugar essential for the construction of protein oligosaccharide chains. In the present study, an in vitro therapeutic approach was used, based on GDP-Man-loaded poly (D,L-lactide-co-glycolide) (PLGA) nanoparticles (NPs), which were used to treat CDG-Ia fibroblast cultures, thus bypassing the glycosylation pathway reaction catalysed by PMM2. To assess the degree of hypoglycosylation in vitro, the present study examined the activities of $\alpha$-mannosidase, $\beta$-glucoronidase and $\beta$-galactosidase in defective and normal fibroblasts. GDP-Man (30 $\mu \mathrm{g} / \mathrm{ml}$ GDP-Man PLGA NPs) was incubated for $48 \mathrm{~h}$ with the cells and the specific activities of $\alpha$-mannosidase and $\beta$-galactosidase were estimated at 69 and $92 \%$ compared with healthy controls. The residual activity of $\beta$-glucoronidase increased from 6.5 to $32.5 \%$ and was significantly higher compared with that noted in the untreated CDG-Ia fibroblasts. The glycosylation process of fibroblasts was also analysed by two-dimensional electrophoresis. The results demonstrated that treatment caused the reappearance of several glycosylated proteins. The data
\end{abstract}

Correspondence to: Dr Giovanni Maria Severini, Institute for Maternal and Child Health-IRCCS 'Burlo Garofolo', Via dell'Istria 65/1, I-34137 Trieste, Italy

E-mail: gianmaria.severini@burlo.trieste.it

*Contributed equally

Key words: congenital disorder of glycosylation type Ia, poly (D,L-lactide-co-glycolide) nanoparticles, guanosine-diphosphatemannose, hypoglycosylation, enzymatic assays in vitro showed that GDP-Man PLGA NPs have desirable efficacy and warrant further evaluation in a preclinical validation animal model.

\section{Introduction}

Congenital disorder of glycosylation type Ia (CDG-Ia) is a rare autosomal recessive multisystem disorder with severe neurological disabilities (encephalopathy and psychomotor retardation) due to mutations in the phosphomannomutase 2 (PMM2) gene, which encodes for an enzyme involved in the isomerization of mannose-6-phosphate (M6P) to mannose-1-phosphate (M1P). In this metabolic pathway, M1P is the precursor of guanosine 5'-diphospho-D-mannose (GDP-Man). GDP-Man is the substrate of the enzyme mannose-1-phosphate guanylyltransferase $\alpha$, which is crucial for protein $\mathrm{N}$-glycosylation (Fig. 1). The mutated PMM2 gene leads to a decreased conversion of M6P to M1P, corresponding to limited synthesis of GDP-Man in the cytoplasm. GDP-Man is a key substrate in glycoprotein formation and is involved in several reactions catalysed by the N-glycosylation pathway. Therefore, it is used directly or indirectly as a mannose donor for all mannosylation reactions. Decreased GDP-Man results in the hypoglycosylation of newly synthesised proteins with a limited number of branched oligosaccharide chains linked to asparagine amino groups.

$\mathrm{N}$-glycosylation is a post-translational modification that is important in determining protein structure and function. Several proteins, including lysosomal enzymes, serum proteins and membrane glycoproteins, are sensitive to hypoglycosylation $(1,2)$. Therefore, the lack of mannosylation disrupts the lysosomal enzyme cycle, resulting in low enzyme concentration levels within the cells and abnormally increased levels in the extracellular fluids and serum. Previous studies have examined the activity of several lysosomal enzymes in the serum and leukocytes of patients with CDG-Ia (1). Barone et al demonstrated that the enzymatic activities of $\beta$-galactosidase, $\beta$-glucuronidase, $\beta$-hexosaminidase and arylsulfatase $A$ in the serum of patients were increased between 2- and 4-fold compared with those of normal subjects. However, in CDG-Ia leukocytes, the activities of other enzymes, including 
$\alpha$-fucosidase, $\beta$-glucuronidase and $\alpha$-mannosidase, were reduced (1). These findings demonstrated an alteration of the intra- and extracellular lysosomal enzyme activity levels in patients with CDG-Ia, as a consequence of the disturbed isomerization of M6P to M1P (1-3).

The current treatment options used for the symptoms caused by CDG-Ia are inefficient. Enzyme replacement therapy (ERT) can be an available treatment for patients with CDG-Ia by the modification of PMM2 and the attachment of a transduction domain which allows the nanoparticle to cross biological membranes $(4,5)$. Alternatively, it can utilise molecules to improve PMM2 uptake (6). Unfortunately, the low stability of compounds in serum and the presence of the blood-brain barrier (BBB) render ERT a therapeutic strategy with limited success. Additional attempts to treat PMM2 deficiency have been reported (7), including gene therapy, dietary mannose supplementation, and phosphomannose isomerase inhibitors that increase the availability of M6P. The addition of $1 \mathrm{mM}$ Man to the fibroblasts of patients with CDG-Ia is able to ameliorate the glycosylation defect and restore the deficient levels of GDP-Man (8).

Patients with CDG-Ia do not respond well to treatment (9-11); this is due to the fact that Man-1-P is a compound that cannot cross the cell membrane. Therefore, the use of a derivative that can pass via the cell membrane may re-establish the level of GDP-Man that is necessary for correct protein glycosylation (8-12). Therefore, the present study examined the possibility of direct treatment with GDP-Man, by bypassing the reaction catalysed by PMM2. This approach was used by in vitro administration of poly (D,L-lactide-co-glycolide) (PLGA) nanoparticles (NPs), which can overcome the drawbacks associated with the low stability of the compound. It is widely recognised that PLGA nanoparticle vectors exhibit optimal physicochemical properties, including high biodegradability and biocompatibility with tissues and cells and low toxicity (13). The use of the PLGA polymers was approved by the Food and Drug administration and the European Medicine Agency in different clinical protocols of drug delivery in humans (14). It has been shown that these compounds can cross the BBB $(15,16)$. In the present study, a therapeutic strategy was proposed to treat CDG-Ia in fibroblast cultures using PLGA NPs loaded with GDP-Man, which is a nucleotide-activated sugar essential for the production of oligosaccharide chains. The effects of this approach were assessed in human deficient fibroblasts, prior to and following treatment with GDP-Man-NPs, by measuring the activities of several lysosomal enzymes that were impaired in this pathway.

\section{Materials and methods}

PLGA NP preparation. PLGA was used according to the protocol provided by the manufacturer (Boehringer-Ingelheim, Ingelheim am Rhein, Germany). PLGA conjugated with Rhodamine B piperazine amide (R-PLGA; Sigma-Aldrich; Merck KGaA, Darmstadt, Germany) was prepared as previously described (17). Poly vinyl alcohol (PVA; 13-15,000 Da, degree of hydrolysation $86-89 \mathrm{Mol} \%$, viscosity at $4 \% \mathrm{w} / \mathrm{v}$ in water 3.5-4.5 cps) and the solvents (HPLC grade) used for analyses were purchased from Sigma-Aldrich; Merck KGaA.
Lyophilised guanosine 5'-diphospho-D-mannose sodium salt (GDP-Man, Sigma-Aldrich; Merck KGaA) was re-suspended in water for injectable preparations (Galenica Senese, Monteromi d'Arbia, Italy). The final concentration of the solution was $10 \mathrm{mg} / \mathrm{ml}$ of GDP-Man. The GDP-Man-loaded PLGA NPs were prepared using the W/O/W (double emulsion) solvent evaporation method $(18,19)$. A total of $500 \mu \mathrm{l}$ of GDP-Man solution were emulsified in $2 \mathrm{ml}$ of dichloromethane (DCM; Sigma-Aldrich; Merck KGaA) solution containing polymer (47.5 mg of PLGA and $2.5 \mathrm{mg}$ of R-PLGA at $5^{\circ} \mathrm{C}$ ) using a probe sonicator (MicrosonUltrasonic cell disruptor, Misonix, Inc. Farmingdale, NY, USA) at $100 \mathrm{~W}$ for $30 \mathrm{sec}$ to obtain the $\mathrm{W}_{1} / \mathrm{O}$ emulsion (first inner emulsion). The first inner emulsion was rapidly added to $8.5 \mathrm{ml}$ of $1 \%$ (w:v) PVA aqueous solution and the $\mathrm{W}_{1} / \mathrm{O} / \mathrm{W}_{2}$ emulsion was formed under sonication $(100 \mathrm{~W}$ for $60 \mathrm{sec})$ at $5^{\circ} \mathrm{C}$. The preparation was mechanically stirred $(1,400 \mathrm{rpm})$ for at least $3 \mathrm{~h}$ (RW20DZM, Janke \& Kunkel IKA-Labortechnik, Staufen, Germany) at room temperature until complete solvent evaporation. The GDP-Man-loaded PLGA NPs (sample B1) were recovered and purified, to remove the un-encapsulated GDP-Man and PVA, by hi-speed centrifugation (Beckman Coulter, Inc., Brea, CA, USA) at 15,000 rpm for $10 \mathrm{~min}$ at $5^{\circ} \mathrm{C}$. They were subsequently washed several times with sterile water, re-suspended in physiological solution and used for in vitro experiments. The preparations were stored at $-20^{\circ} \mathrm{C}$ and restored at room temperature by sonication prior to the treatments. Empty NPs (sample B2) were used and were prepared in $500 \mathrm{ml}$ of water, instead of GDP-Man solution, in the presence of the same preparative conditions used for sample B1.

Physico-chemical and technical characterization of NPs. The morphology and the structure/architecture of the samples (B1 and B2) were analysed by scanning transmission electron microscopy (STEM). A drop of sample suspension was placed on a 200-mesh copper grid (TABB Laboratories Equipment, Berkshire, UK) and allowed to adsorb. The suspension surplus was removed using filter paper. All grids were analysed using a Nova NanoSEM 450 (FEI; Thermo Fisher Scientific, Inc., Waltham, MA, USA) transmission electron microscope operating at $30 \mathrm{kV}$. A TEM grid holder was used and the STEM II detector was set in the bright-field mode to analyse the transmitted electrons.

Size and zeta potential ( $\zeta$-pot). The mean particle size (Z-Average) and the polydispersitivity index (PDI) of the samples following purification and re-suspension in physiological solution, were determined at room temperature by photon correlation spectroscopy using a Zetasizer Nano ZS (laser $4 \mathrm{~mW} \mathrm{He-Ne,} 633 \mathrm{~nm}$, laser attenuator automatic, transmission 100-0.0003\%, Avalanche photodiode detector, Q.E. $>50 \%$ at $633 \mathrm{~nm}$ ) from Malvern Instruments, Ltd. (Malvern UK). The results were also expressed as the intensity distribution, i.e. the size 50\% [Di(50)] and 90\% [Di(90)], below which all the NPs were placed. The $\zeta$-pot was measured using the same equipment with a combination of laser Doppler velocimetry and phase analysis light scattering. All data are expressed as the mean of at least three determinations (three for each sample). 


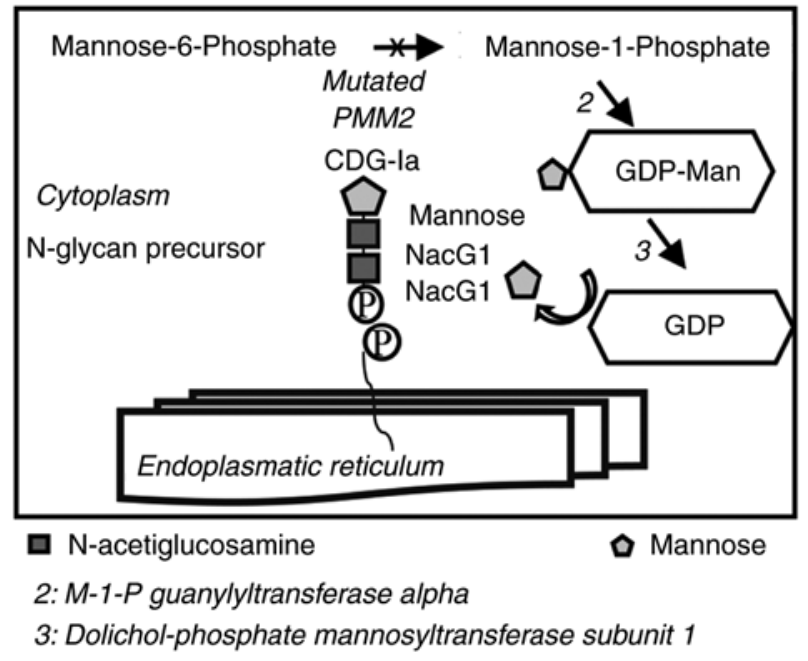

Figure 1. Pathogenetic pathway of CDG-Ia. CDG-Ia, congenital disorder of glycosylation type Ia; PMM2, phosphomannomutase 2; GDP-MAN, guanosine 5'-diphospho-D-mannose.

Residual surfactant. The residual quantity of surfactants (PVA) was determined using a colorimetric method based on the formation of the coloured complex between two adjacent hydroxyl groups of the surfactant and of an iodine molecule (20). The protocol used was reported in a previous study (21).

GDP-Man content. To evaluate the content of GDP-Man, $2 \mathrm{ml}$ of NP suspension was freeze-dried at $-60^{\circ} \mathrm{C}$ and at $1 \times 10^{-3} \mathrm{~mm} / \mathrm{Hg}$ for $48 \mathrm{~h}$ (LyoLab 300, Heto-Holten, Allerod, Denmark). The freeze-dried NPs (10 mg) were dissolved in $1.5 \mathrm{ml}$ of dichloromethane. Subsequently, $3 \mathrm{ml}$ of water were added to the extract of the GDP-Man and the organic solvent was evaporated at room temperature under stirring (1,500 rpm for at least $1 \mathrm{~h}$; RW20DZM, Janke \& Kunkel IKA-Labortechnik). The aqueous solution was filtered (cellulose acetate filter, porosity $0.2-\mu \mathrm{m}$, Sartorius AG, Göttingen, Germany) to remove the polymer residues and was analysed by HPLC in order to evaluate the drug content.

The HPLC apparatus (PerkinElmer, Inc., Waltham, MA, USA) comprised a model series 200 pump with an injection valve and a $200 \mu 1$ sample loop. A UV detector (series 200) was used for the determination of the NP concentration. Chromatography separation was performed on a sunfire C 18 (4.6x150 mm; porosity $5 \mu \mathrm{m}$; Waters Corporation, Milford, MA, USA) column at room temperature and at a flow rate of $1 \mathrm{ml} / \mathrm{min}$. The pump operated in an isocratic mode using a mobile phase of 43:23:36:1 v/v acetonitrile: methanol: water: acetic acid. The chromatographic peak-areas of the standard solutions were collected and used for the generation of the calibration curve. The linearity of the method was achieved in the range of $0.2-10 \mu \mathrm{g} / \mathrm{ml}\left(\mathrm{r}^{2}=0.9982\right)$. All data are expressed as the mean of at least three determinations. Drug loading is expressed as mg of GDP-Man encapsulated/100 mg of NPs.

Cell culture. A total of three CDG-Ia fibroblast cultures (CDG-Ia_F1, CDG-Ia_F2, CDG-Ia_F3) namely F1, F2 and $\mathrm{F} 3$, were obtained from skin biopsies provided by the Cell
Line and DNA Biobank from Patients affected by Genetic Diseases (Centro di Diagnostica Genetica e Biochimica delle Malattie Metaboliche, Istituto G. Gaslini, Genova, Italy). The human fibroblasts were maintained in RPMI 1640 supplemented with $10 \%$ fetal bovine serum, $1 \%$ L-glutamine and $1 \%$ penicillin/streptomycin (all Euroclone, Milano, Italy) at $37^{\circ} \mathrm{C}$ in humidified air containing $5 \% \mathrm{CO}_{2}$. Healthy fibroblasts (HFs) were obtained from skin specimens derived from the circumcision of healthy subjects. Informed consent forms were provided from their parents or legal representatives.

Mutational analysis of the three skin specimens. Genomic DNA was isolated from the fibroblasts of patients with CDG-Ia. Direct DNA sequencing of the fibroblast cultures F1, F2 and F3 demonstrated that patients were compound heterozygous with different percentages of PMM2 residual activity (22-26).

In the F1 fibroblast cultures, the L32R/R123Q mutation was identified. This PMM2 genotype has been demonstrated to reduce PMM 2 activity to $\sim 2.2 \mathrm{mU} / \mathrm{mg}$ compared with normal activity levels, which is estimated to be $5.34 \pm 1.74 \mathrm{mU} / \mathrm{mg}$ of protein $(23,24)$. The fibroblasts of the F2 genotype revealed $\mathrm{R} 14 \mathrm{H} / \mathrm{C} 241 \mathrm{~S}$ mutations with a PMM2 residual activity of $1.7 \mathrm{mU} / \mathrm{mg}$. These two genotypes have been frequently associated with a mild phenotype, which is characterized by cerebellar ataxia, dysmetria and dysarthria $(23,24)$.

In the F3 fibroblasts, R141H/D223N mutations were identified, which have been associated with low PMM2 residual activity (undetectable) causing a severe phenotype of fibroblasts. The majority of patients with the severe phenotype have severe intellectual disability and microcephaly, and they are unable to walk independently $(23,24)$.

\section{3-(4,5-Dimethylthiazol-2-yl) 2,5-diphenyl tetrazolium bromide (MTT) toxicity assay of PLGA GDP-Man. An MTT assay is a colorimetric assay based on the ability of viable cells to reduce the soluble yellow tetrazolium salt, MTT, in order to form a blue formazan crystal by mitochondrial succinate dehydrogenase. The MTT test (Sigma-Aldrich; Merck KGaA) was performed in order to determine the cellular toxicity on fibroblasts following treatment with GDP-Man PLGA NPs. The cell viability was measured using the GLOMAX multi detection system and the UV optical kit (Promega Corporation, Madison, WI, USA) following a 4-h incubation period (27).}

Glycoprotein isolation. A glycoprotein isolation kit using concanavalin A (ConA; Thermo Fisher Scientific, Inc.) was used to separate $\mathrm{N}$-linked glycoproteins from complex protein mixtures, following the manufacturer's protocol. The mix was passed through a column of lectin ConA that was immobilised on agarose. Following washing, the glycoprotein fraction was eluted using buffer ( $2 \%$ SDS and $50 \mathrm{mM}$ Tris- $\mathrm{HCl}, \mathrm{pH}$ 7.4; Sigma-Aldrich; Merck KGaA).

Two-dimensional electrophoresis (2-DE). A total of $46 \mu \mathrm{g}$ of glycoproteins from each sample were denatured in $150 \mu \mathrm{l}$ of dissolution buffer (7 M urea, $2 \mathrm{M}$ thiourea, 4\% CHAPS, $40 \mathrm{mM}$ Tris, $65 \mathrm{mM}$ DTT and $0.24 \%$ Bio-Lyte 3-10) in the presence of bromophenol blue, as previously described (28). Subsequently, 7-cm pH 3.0-10.0 NL (IPG) readystrips (Bio-Rad Laboratories, Inc., Hercules, CA, USA) were rehydrated 

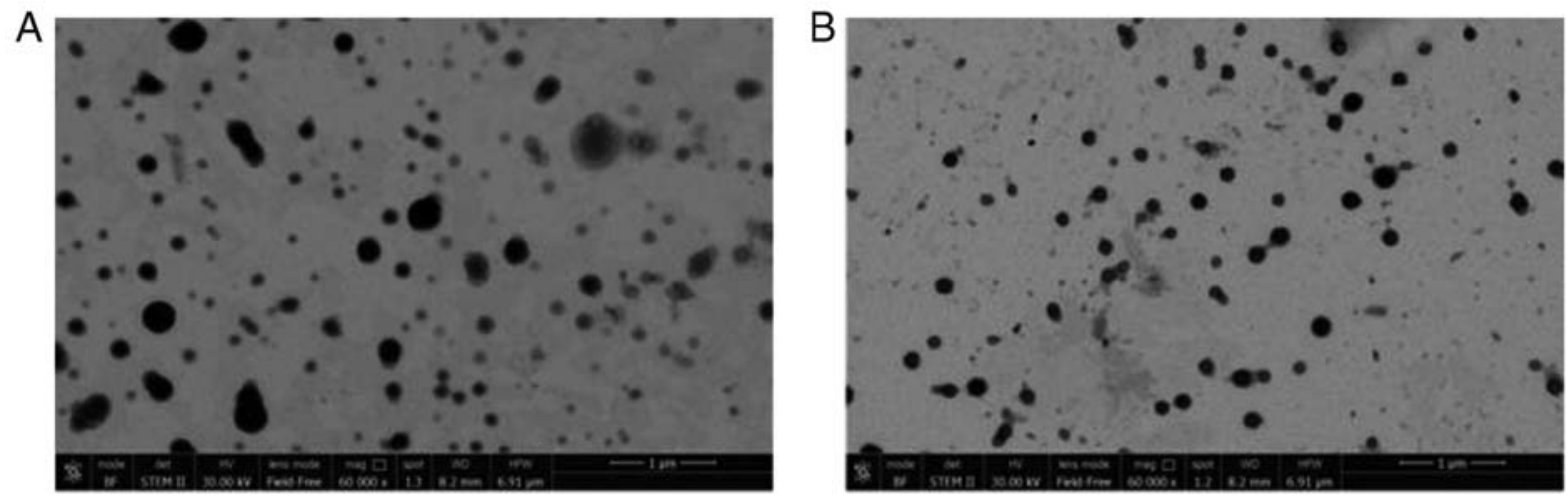

Figure 2. Scanning transmission electron microscopy images (x60,000 magnification) of NPs samples. (A) GDP-Man PLGA NPs_B1 preparation. (B) PLGA NPs_B2 preparation. GDP-MAN, guanosine 5'-diphospho-D-mannose; PLGA NPs, poly (D,L-lactide-co-glycolide) (PLGA) nanoparticles.

at $50 \mathrm{~V}$ for $12 \mathrm{~h}$ at $20^{\circ} \mathrm{C}$. Isoelectric focusing (IEF) was performed in a protein IEF Cell (Proteane IEF Cells; Bio-Rad Laboratories, Inc.). Following IEF, the IPG strips were equilibrated by serial incubations $(15 \mathrm{~min})$ in equilibration buffer (6 $\mathrm{M}$ urea, 2\% SDS, $50 \mathrm{mM}$ Tris- $\mathrm{HCl} \mathrm{pH} 8.8,30 \%$ glycerol, and $1 \%$ DTT) and in equilibration buffer containing $4 \%$ iodoacetamide instead of DTT. The equilibrated IPG strips were transferred to a $12 \%$ polyacrylamide gel for electrophoresis. The 2-DE was run on a Mini-Protean 3 Cell (200 V constant voltage) until the bromophenol blue reached the bottom of the gel. Following protein fixation for $5 \mathrm{~h}$ in $40 \%$ methanol and $10 \%$ acetic acid, the gels were stained for $15 \mathrm{~h}$ with Sypro Ruby (Bio-Rad Laboratories, Inc.). The molecular masses were determined using precision protein standard markers (Bio-Rad Laboratories, Inc.), covering a range of $10-250 \mathrm{kDa}$. The 2-DE gels were scanned with a Molecular Imager PharosFX system and analysed using the Proteomeweaver 4 program (Bio-Rad Laboratories, Inc.)

Lysosomal enzyme activity assays. The proteins were extracted from cells using mammalian protein extraction reagent solution, following the protocol recommended by the manufacturer (Thermo Fisher Scientific Inc.). The specific activities of $\beta$-galactosidase, $\alpha$-mannosidase, $\beta$-mannosidase and $\beta$-glucuronidase were measured using 4-methyl-umbelliferyl $\beta$-D-galactopyranoside, 4-methyl-umbelliferyl $\alpha$-d-mannopyranoside, 4 -methyl-umbelliferyl $\beta$-d-mannopyranoside and 4-methyl-umbelliferyl- $\beta$-d-glucuronidase substrates (Sigma-Aldrich; Merck KGaA). The 4-methyl-umbelliferyl- $\beta$ D-galactopyranoside and 4-methyl-umbelliferyl- $\alpha$-d-mannopi ranoside substrates were used at final concentrations of 1.5 and $3 \mathrm{mM}$ in a buffer containing $0.1 \mathrm{M}$ citric acid and $0.20 \mathrm{M}$ sodium-phosphate ( $\mathrm{pH} 4.5)$. The 4-methyl-umbellifery $1-\beta$-d-mannopyranoside substrate was used at the final concentration of $2.5 \mathrm{mM}$ in a buffer containing $0.1 \mathrm{M}$ citric acid and $0.20 \mathrm{M}$ sodium-phosphate buffer at a $\mathrm{pH}$ of 4.7 .

The reactions were performed in triplicate in 96-well black multiplates (Corning 96-Well Black) provided from Euroclone (Milan, Italy) with a final volume of $60 \mu \mathrm{l}$ (substrate $40 \mu \mathrm{l}$ and sample $20 \mu \mathrm{l}$ ) for $30 \mathrm{~min}$ at $37^{\circ} \mathrm{C}$, with the exception of 4-methyl-umbelliferyl- $\beta$-d-mannopyranoside and 4-methyl -umbelliferyl- $\beta$-d-glucuronidase substrates. In these cases, the reactions were performed for $60 \mathrm{~min}$ at $37^{\circ} \mathrm{C}$. Each reaction mixture was terminated by the addition of $0.290 \mathrm{ml}$ of $0.4 \mathrm{M}$ glycine- $\mathrm{NaOH}$ buffer at $\mathrm{pH} 10.4$. The fluorescence of the released 4-methyl-umbelliferyl was measured using a GLOMAX Multi Detection system and a fluorescence optical kit (Promega Corporation), which was set at an excitation wavelength of $360 \mathrm{~nm}$ and an emission wavelength of $450 \mathrm{~nm}$. The protein concentration of the cellular extracts was determined with the Lowry assay using a PerkinElmer Lamda $40 \mathrm{UV} / \mathrm{VIS}$ spectrophotometer. The enzymatic activity in the fibroblast cultures is expressed as nmol of substrate hydrolysed per/min and normalised per mg of protein.

Statistical analysis. All values of the in vitro experiments are reported as the mean \pm standard deviation. Three experimental replicates were performed per sample. Student's unpaired t-test was used to compare the activity of $\alpha$-mannosidase, $\beta$-glucuronidase and $\beta$-galactosidase between untreated and treated CDG-Ia fibroblasts. $\mathrm{P}<0.01$ was considered to indicate a statistically significant difference. The statistical analysis was performed using the PRISM6 program (GraphPad Software, Inc., La Jolla, CA, USA).

\section{Results}

GDP-Man NPs characterization. In the present study, PLGA NPs were produced that contained GDP-Man (GDP-Man NPs). Several technological conditions, including the volume of inner, the organic and external phases, the concentration of the polymers, the surfactant and drug concentration, and the time and potency of sonication were optimised in order to achieve the optimal preparative results in terms of size, polidispersivity and drug content (data not shown). B1 GDP-Man loaded NPs) and B2 (unloaded NPs) samples were selected and assessed, which were prepared as described above. The results of the physico-chemical characterization are shown in Fig. 2A and B and Table I. The GDP-Man NPs (B1 sample) had a higher PDI value $(0.18$, vs. 0.05$)$ compared with that of the empty NPs (B2 sample). In addition, the $\mathrm{Z}$-Average values and the wide size distribution (D90) increased from 200 to $300 \mathrm{~nm}$ and from 285 to $440 \mathrm{~nm}$, respectively, indicating a major heterogeneity of B1 that typically occurred during drug encapsulation. These data confirmed the presence of well-formed spheric-like structures in the B1 samples, which exhibited higher heterogeneity 
in terms of shape and size in comparison with the B2 samples. In addition, the $\zeta$-pot of $\mathrm{B} 1(\sim 7.5 \mathrm{mV})$ was decreased following drug loading compared with that of B2 $(\sim 2 \mathrm{mV})$, possibly due to a different reorganization of the polymer with the drug into the matrix-like structure of NPs, and due to the possible absorption of GDP-Man on the NP surface.

GDP-Man PLGA NPs do not reduce the viability of human skin fibroblasts. The B1 parameters were optimal with regard to the cellular uptake, as described previously (29). In addition, NPs that are suitable for in vivo application exhibit a particle size ranging between 100 and $350 \mathrm{~nm}$ (30). These structures are favourable in terms of the circulation stability, the interaction with cells and the reduced elimination by the kidneys (30). The present study produced an NP content of $\sim 27.7 \mu \mathrm{g}$ of GDP-Man/100 mg (Table I).

Subsequently, the in vitro toxicity of the GDP-Man NPs was assayed by the addition of different concentrations of B1 NPs to F3 (severe phenotype) fibroblasts. The NP content ranged between 0.75 and $300 \mu \mathrm{g} / \mathrm{ml}$, corresponding to $0.4-150 \mathrm{ng} / \mathrm{well}$ of GDP-Man in the culture medium, as determined by HPLC analysis conducted on NP samples. Following $48 \mathrm{~h}$ of incubation with five different concentrations of $\mathrm{B} 1$ preparation, there was no significant decrease in the viability of the fibroblasts compared with that of the untreated cultures (Fig. 3).

Identification of lysosomal enzyme activity reductions in $C D G$-Ia fibroblasts. The ability of the GDP-Man NPs to restore the $\mathrm{N}$-glycosylation of glycoproteins, was further examined. The three deficient cultures, namely F1, F2 and F3, were assayed and the pattern of lysosomal enzymes deficits was assessed by comparing the specific activity of several lysosomal enzymes with that of healthy fibroblasts. As shown in Fig. 4 , it was found that the $\beta$-galactosidase, $\alpha$-mannosidase, $\beta$-glucuronidase, and $\beta$-mannosidase activities were significantly lower in the CDG-Ia fibroblasts than in the control samples in all three cultures investigated. The normal mean level of $\alpha$-mannosidase specific activity was $0.25 \pm 0.051 \mathrm{mU} / \mathrm{mg}$, whereas levels in the F1, F2 and F3 cultures were estimated to be $0.035-0.020 \pm 0.001 \mathrm{mU} / \mathrm{mg}$. The normal mean level of the $\beta$-glucuronidase activity was $0.476 \pm 0.064 \mathrm{mU} / \mathrm{mg}$, whereas the levels were estimated to be $0.026-0.018 \pm 0.004 \mathrm{mU} / \mathrm{mg}$ in the F1, F2 and F3 cultures. The normal mean level of $\beta$-mannosidase activity was $0.540 \pm 0.005 \mathrm{mU} / \mathrm{mg}$, which was reduced to $0.164-0.120 \pm 0.002 \mathrm{mU} / \mathrm{mg}$ in the $\mathrm{F} 1, \mathrm{~F} 2$ and F3 cultures.

A previous study (1) determined that the activity of the $\beta$-galactosidase enzyme was not reduced in the sera and leukocytes of patients with CDG-Ia. Therefore, this activity of this enzyme was not initially considered to determine the in vitro correction of glycosylation. However, all three CDG-Ia fibroblast cultures indicated a significant decrease in $\beta$-galactosidase activity, which was estimated to be 7-10 times lower than that of the HFs. The normal range of $\beta$-galactosidase activity in HFs was estimated to be $1.62 \pm 0.021 \mathrm{mU} / \mathrm{mg}$, whereas this was decreased to $0.40-0.20 \pm 0.013 \mathrm{mU} / \mathrm{mg}$ in the F1, F2 and F3 cultures (Fig. 4). Therefore, three fibroblast cultures, F1, F2 and F3 were established; F1 and F2 were associated with the mild phenotype, whereas F3 was associated with the severe phenotype. 


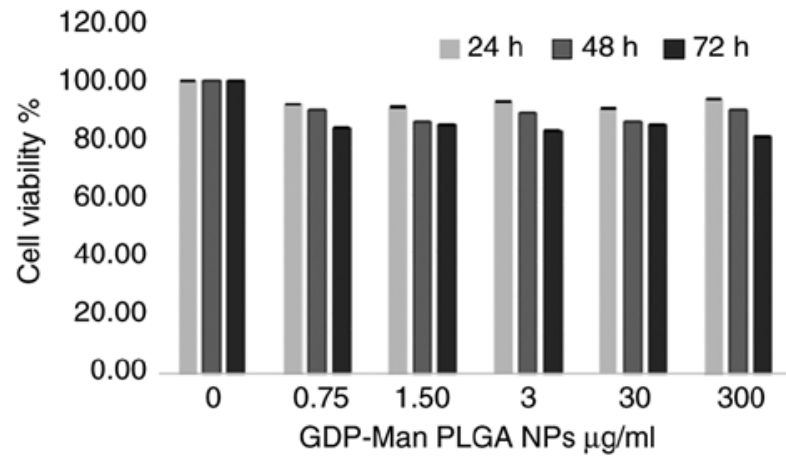

Figure 3. Cell viability. 3-(4,5-Dimethylthiazol-2-yl) 2,5-diphenyl tetrazolium bromide assay of human skin fibroblasts following 24,48 and $72 \mathrm{~h}$ of treatment with five different concentrations of GDP-Man-PLGA NPs. GDP-Man-PLGA NPs, guanosine 5'-diphospho-D-mannose-loaded poly (D,L-lactide-co-glycolide) nanoparticles.

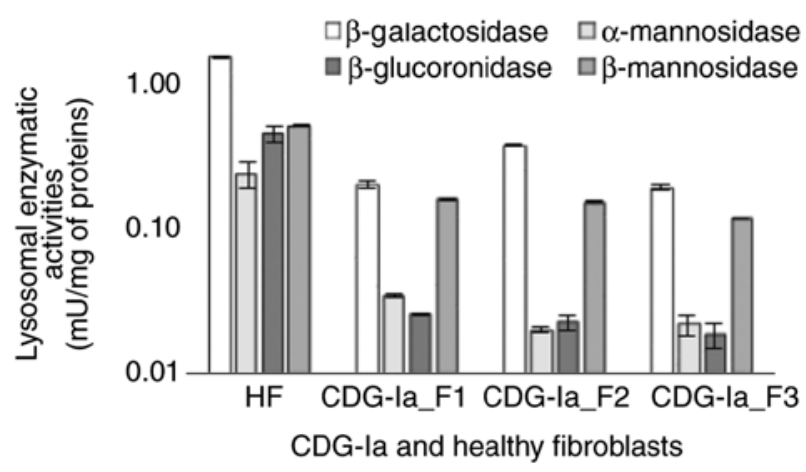

Figure 4. Enzymatic activity assay (logarithmic scale) of four lysosomal enzymes was conducted as follows: $\beta$-galactosidase $\alpha$-mannosidase, $\beta$-glucuronidase and $\beta$-mannosidase activity levels were measured a $\mathrm{mU} / \mathrm{mg}$ of protein. CDG-Ia_F1, CDG-Ia_F2 and CDG-Ia_F3 indicate untreated fibroblast cultures. HF, healthy fibroblasts; CDG-Ia, congenital disorder of glycosylation type Ia.

Identification of optimal dose and incubation time. The capacity of the GDP-Man NPs to ameliorate glycosylation deficits was examined by treating the three F1, F2 and F3 cultures with the $\mathrm{B} 1$ preparation. Prior to conducting the assays, the optimum concentration of GDP-Man NPs and the optimum incubation time period were determined. Finally, the time period required to restore the lysosomal activity was determined. These parameters were used in the 'in vitro therapeutic protocol'.

Rush et al (31) reported that the average GDP-Man contents in normal and CDG-Ia fibroblasts were 23 and $2.3 \mathrm{pmol} / 10^{6}$ cells, respectively, which corresponded to 14 and $1.4 \mathrm{ng}$ of GDP-Man, respectively. According to these results, $2 \times 10^{5}$ cells of F1, F2 and $\mathrm{F} 3$ were cultured in 6-multiwell plates and were used for the experiments below. The three cultures were treated with GDP-Man NPs containing either $150 \mathrm{ng}(300 \mu \mathrm{g} / \mathrm{ml}$ of B1 NPs) or $15 \mathrm{ng}(30 \mu \mathrm{g} / \mathrm{ml}$ of B1 NPs) of GDP-Man. Furthermore, the CDG-Ia fibroblasts were treated with a quantity of GDP-Man five times higher than that in the $1 \times 10^{6} \mathrm{HFs}(32)$.

Incubation durations of 3 and $6 \mathrm{~h}$ were assessed. Following overnight post-incubation with conditioned medium, the F1 (GDP-Man NPs), F2 (GDP-Man NPs), F3 (GDP-Man NPs) and $\mathrm{HF}$ cultures were harvested and total proteins were extracted. The specific activities of several lysosomal enzymes were assayed. The $\alpha$-mannosidase activity of the HFs was estimated to be $0.25 \pm 0.051 \mathrm{mU} / \mathrm{mg}$, whereas those of the F1, F2 and F3 fibroblasts were estimated to be $0.026 \pm 0.001 \mathrm{mU} / \mathrm{mg}$. As shown in Fig. 5, the $\alpha$-mannosidase activity increased between 3- and 4-fold in all three F1 (GDP-Man NPs), F2 (GDP-Man NPs), F3 (GDP-Man NPs) cultures. Notably, the $\alpha$-mannosidase activity value of the F1 (GDP-Man NPs) culture was estimated to be $0.172 \pm 0.021 \mathrm{mU} / \mathrm{mg}$, which corresponded to $69 \%$ of normal activity. Therefore, the F1 (GDP-Man NPs_15 ng) culture indicated a significant increase of $\alpha$-mannosidase activity following $6 \mathrm{~h}$ treatment of $15 \mathrm{ng} /$ well of GDP-Man (30 $\mu \mathrm{g} / \mathrm{ml}$ GDP-Man-PLGA NPs) in conditioned medium and $24 \mathrm{~h}$ post-incubation. Incubation of the fibroblasts with $150 \mathrm{ng} /$ well of GDP-Man $(300 \mu \mathrm{g} / \mathrm{ml}$ GDP-Man-PLGA NPs) did not cause a linear improvements in $\alpha$-mannosidase activity. Therefore, $15 \mathrm{ng} /$ well of GDP-Man was selected as the optimal concentration used in the subsequent assays. In contrast to these findings, incubation of the fibroblasts for $6 \mathrm{~h}$ resulted in higher activity levels than those noted at $3 \mathrm{~h}$ (33). Therefore, $6 \mathrm{~h}$ was selected as the optimal time period for the following assessments.

In order to ensure that the effect observed was not obtained by simple supplementation of free GDP-Man to the medium, $150 \mathrm{ng}$ of free GDP-Man was added to the medium of the F1, F2 and F3 cultures under the same experimental conditions. No significant increase in $\alpha$-mannosidase activity was observed for the F1 GDP-Man, F2 GDP-Man and F3 GDP-Man fibroblasts, which confirmed that free GDP-Man did not affect glycosylation without the use of the PLGA carrier. When adding PLGA NPs to F1, F2 and F3, no increase in the enzymatic activity of $\alpha$-mannosidase was observed (Fig. 5). Therefore, the loading of GDP-Man in PLGA NPs was required for efficient delivery and increase in the protein glycosylation levels. No lysosomal enzyme activity was detected in the media of the treated or untreated fibroblasts.

Evaluation of post-incubation time necessary to correct the lysosomal enzyme activities. According to the aforementioned findings, the time period required to correct the glycosylation of proteins was determined by assaying the specific activity of $\alpha$-mannosidase at the three time points $(24,48$ and $72 \mathrm{~h}$ ) following $6 \mathrm{~h}$ of incubation with $15 \mathrm{ng} /$ well of GDP-Man loaded in PLGA NPs. The activities of the $\alpha$-mannosidase enzyme in the F1 (GDP-Man NPs), F2 (GDP-Man NPs) and F3 (GDP-Man NPs) cultures were similar to those of the HFs at $48 \mathrm{~h}$ post-incubation and were marginally decreased following $72 \mathrm{~h}$ of incubation (Fig. 6). Therefore the 48 -h period was selected as the standard post-incubation time period used in the experimental assays.

The activity of the lysosomal enzyme, $\beta$-glucuronidase, was also detected; low activity was observed in the F3 fibroblasts $(0.0246 \pm 0.002 \mathrm{mU} / \mathrm{mg})$ compared with that noted in the HFs $(0.476 \pm 0.006 \mathrm{mU} / \mathrm{mg})$. Following treatment with NPs, $\beta$-glucuronidase activities in the F1 (GDP-Man NPs), F2 (GDP-Man NPs) and F3 (GDP-Man NPs) fibroblasts were higher than those in the F1, F2 and F3 groups (Fig. 7). The F1, $\mathrm{F} 2$ and $\mathrm{F} 3$ groups were incubated for $48 \mathrm{~h}$ in the presence of $15 \mathrm{ng} /$ well of GDP-Man (30 $\mu \mathrm{g} / \mathrm{ml}$ of GDP-Man-PLGA NPs). 


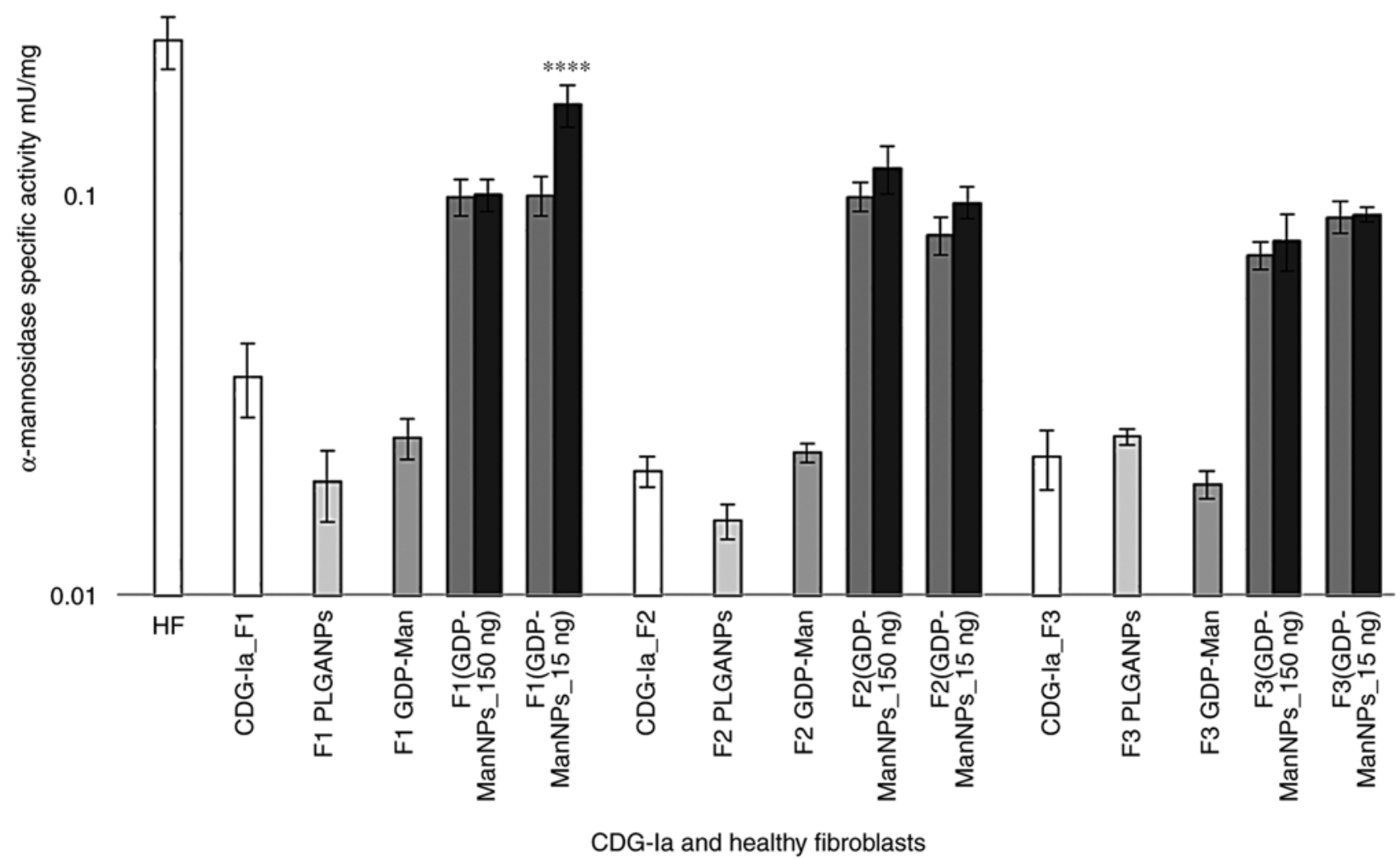

Figure 5. Dose and incubation time. The enzymatic activity (logarithmic scale) of $\alpha$-mannosidase was measured as $\mathrm{mU} / \mathrm{mg}$ of protein following treatment with $150 \mathrm{ng} /$ well and $15 \mathrm{ng} /$ well of GDP-Man loaded in PLGA NPs. The increase of the $\alpha$-mannosidase activity was significant $(\mathrm{P}<0.0001)$ between the untreated CDG-Ia_F1, CDG-Ia_F2 and CDG-Ia_F3 and the treated F1_GDP-Man NPs, F2_GDP-Man NPs and F3_GDP-Man NPs preparations. The activity levels were assessed $24 \mathrm{~h}$ following treatment. ${ }^{* * * * *} \mathrm{P}<0.0001$ among untreated and treated fibroblast cultures. HF, healthy fibroblasts; CDG-Ia, congenital disorder of glycosylation type Ia; GDP-Man, guanosine 5'-diphospho-D-mannose; PLGA, poly (D,L-lactide-co-glycolide); NPs, nanoparticles.

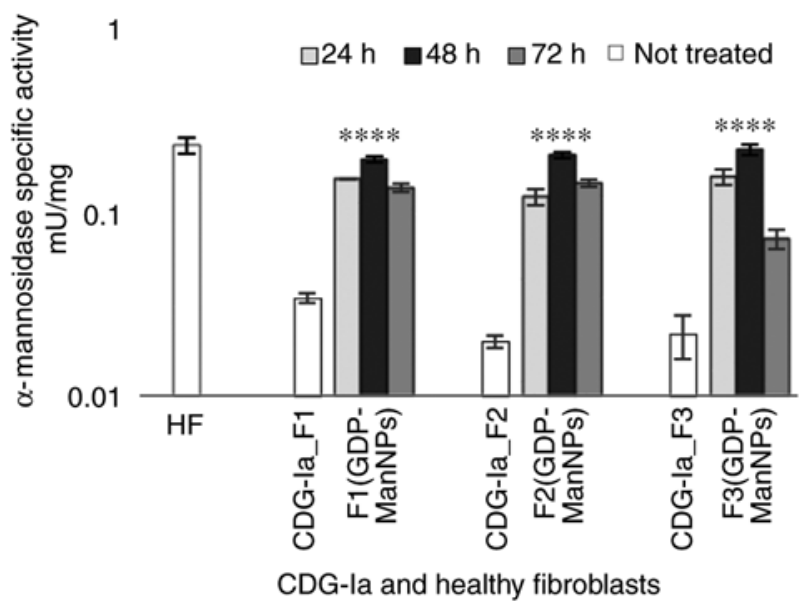

Figure 6. Post-incubation time. The specific activity levels of $\alpha$-mannosidase are expressed as $\mathrm{mU} / \mathrm{mg}$ of protein and were monitored for a period of 3 days. The activities of untreated CDG-Ia_F1, CDG-Ia_F2 and CDG-Ia_F3, were significantly higher at $48 \mathrm{~h}$ compared with the other two post-incubation time points $(\mathrm{P}<0.0001) .{ }^{* * * *} \mathrm{P}<0.0001$ among untreated and treated fibroblast cultures. HF, healthy fibroblasts; CDG-Ia, congenital disorder of glycosylation type Ia; GDP-Man, guanosine 5'-diphospho-D-mannose; PLGA, poly (D,L-lactide-co-glycolide); NPs, nanoparticles.
Subsequently, the F1 (GDP-Man NPs) and F3 (GDP-Man NPs) $\beta$-glucuronidase activity reached $0.130 \mathrm{mU} / \mathrm{mg}$, which corresponded to $32.5 \%$ of the normal activity compared with that noted in the $F 1, F 2$ and $F 3$ groups.

Finally the F1 (GDP-Man NPs), F2 (GDP-Man NPs) and F3 (GDP-Man NPs) were incubated at $48 \mathrm{~h}$ with $15 \mathrm{ng} /$ well of GDP-Man (30 $\mu \mathrm{g} / \mathrm{ml}$ of GDP-Man-PLGA NPs) and their $\beta$-galactosidase activities were increased 5-7-fold compared with those noted in F1, F2 and F3 (Fig. 8). Their levels were comparable to those of the HFs.

To rule out that an increase in enzymatic activity corresponds to higher production of protein, the lysosomal mRNA levels were determined. Ichisaka et al demonstrated an increase in the mRNA expression levels of $\beta$-hexosaminidase, which corresponded to an increase in the $\beta$-hexosaminidase $\alpha$-chain subunit (3). The present study aimed to quantify the mRNA expression levels of $\alpha$-mannosidase, $\beta$-gluocoronidase and $\beta$-galactosidase (34). No significant variations in mRNA levels were observed among the F3 cells treated with GDP-Man PLGA NPs and the F3 cells treated with single PLGA NPs. Based on these results, it was confirmed that an improvement 


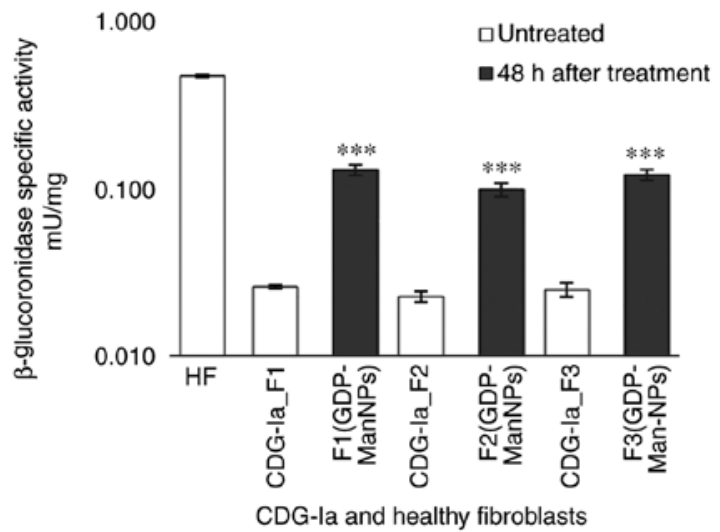

Figure 7. $\beta$-glucuronidase activity. The enzymatic activity levels of $\beta$-glucuronidase are expressed as $\mathrm{mU} / \mathrm{mg}$ of protein and were analysed following $48 \mathrm{~h}$ of incubation. The increase in the activity levels was significant $(\mathrm{P}<0.001)$ among the following groups: Untreated CDG-Ia_F1, CDG-Ia_F2 and CDG-Ia_F3, and treated F1_GDP-Man NPs, F2_GDP-Man NPs and F3_GDP-Man NPs. ${ }^{* * *}$ P $<0.001$ among untreated and treated fibroblast cultures.

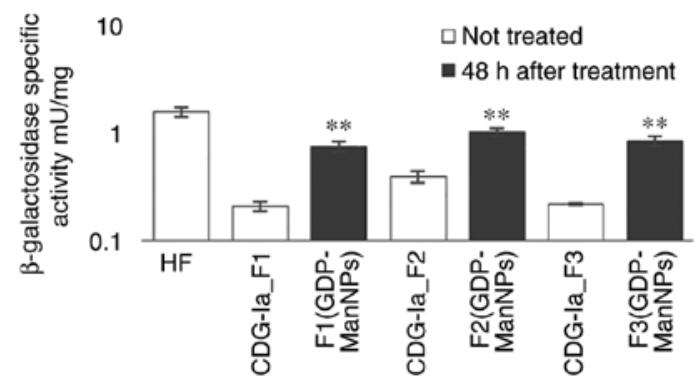

CDG-la and healthy fibroblasts

Figure 8. $\beta$-galactosidase specific activity is expressed in $\mathrm{mU} / \mathrm{mg}$ of protein and was analysed following $48 \mathrm{~h}$ of incubation. The treatment of the fibroblasts with GDP-Man led to a significant increase $(\mathrm{P}<0.01)$ in the activity levels noted in the following groups: F1_GDP-Man NPs, F2_GDP-Man NPs and F3_GDP-Man NPs compared with those noted in the untreated CDG-Ia_F1, CDG-Ia_F2 and CDG-Ia_F3 fibroblasts. ${ }^{* *} \mathrm{P}<0.01$ among untreated and treated fibroblast cultures. HF, healthy fibroblasts; CDG-Ia, congenital disorder of glycosylation type Ia; GDP-Man, guanosine 5'-diphospho-D-mannose; PLGA, poly (D,L-lactide-co-glycolide); NPs, nanoparticles.

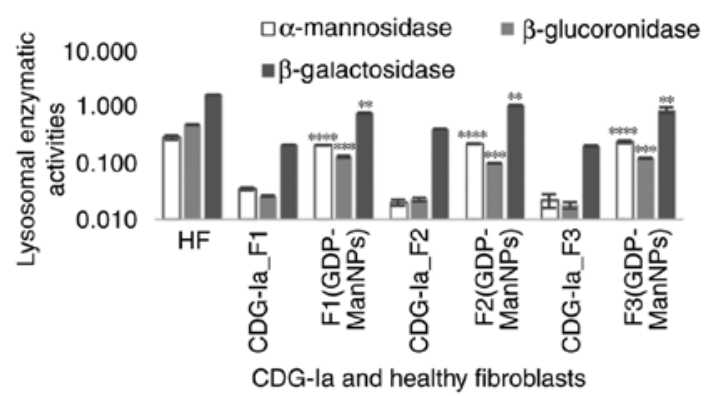

Figure 9. Specific activities of $\alpha$-mannosidase, $\beta$-glucuronidase and $\beta$-galactosidase are expressed as $\mathrm{mU} / \mathrm{mg}$ of protein and were analysed $48 \mathrm{~h}$ following incubation. The increase in the specific activity levels of these lysosomal enzymes in the treated fibroblasts F1_GDP-Man NPs, F2_GDP-Man NPs and F3_GDP-Man NPs was significant $(\mathrm{P}<0.01, \mathrm{P}<0.001$ and $\mathrm{P}<0.0001)$ compared with the levels noted in the defective fibroblasts (untreated CDG-Ia_F1, CDG-Ia_F2 and CDG-Ia_F3) following $54 \mathrm{~h}$ of incubation. ${ }^{* *} \mathrm{P}<0.01,{ }^{* * * *} \mathrm{P}<0.001$ and ${ }^{* * * *} \mathrm{P}<0.0001$ among untreated and treated fibroblast cultures. HF, healthy fibroblasts; CDG-Ia, congenital disorder of glycosylation type Ia; GDP-Man, guanosine 5'-diphospho-D-mannose; PLGA, poly (D,L-lactide-co-glycolide); NPs, nanoparticles. of lysosomal specific activity does not depend on an increase in protein quantity, as the mRNA production and expression levels did not alter following $48 \mathrm{~h}$ of treatment with GDP-Man PLGA NPs. The details regarding the exact methodological approach are available upon request.

The results reported in the present study confirmed that GDP-Man NPs are internalised by CDG-Ia fibroblasts and metabolised accordingly. It is noteworthy that the selected quantity of GDP-Man was sufficient to partially restore the in vitro $\mathrm{N}$-glycosylation. The protein glycosylation pattern was improved and several lysosomal enzymes increased in activity following a single treatment (Fig. 9).

2-DE map of glycoproteins prior to and following treatment. In order to confirm the restoration of N-hypoglycosylation following treatment, the bulk of the extracted proteins were used to analyse the glycosylation pattern of the CDG-Ia fibroblasts. Total proteins were extracted from the $\mathrm{F} 3$ and HF cultures, and the glycosylated protein fraction was separated as described above. Subsequently, the glycosylation patterns between F3 and HF were examined (32). Approximately 450 glycoprotein spots were detected in the 2-DE gels and the correlation of gel-pairs performed allowed an average matching efficiency of $\sim 81 \%$. The 2-DE map analysis revealed nine glycoprotein spots present in the HF culture (Fig. 10A) that were absent in the F3 culture (Fig. 10B).

The F3 culture was incubated for $6 \mathrm{~h}$ with $15 \mathrm{ng} /$ well of GDP-Man (30 $\mu \mathrm{g} / \mathrm{ml}$ of GDP-Man-PLGA NPs). The conditioned medium was subsequently replaced with fresh medium. At $48 \mathrm{~h}$ post-incubation, the cells were harvested and the glycosylated proteins were separated. Eelectrophoretic analysis of the glycoprotein extracts of HFs (Fig. 10A), F3 prior to treatment (Fig. 10B) and F3 (GDP-Man NPs) following treatment (Fig. 10C) were analysed. The results indicated that, following treatment, the F3 (GDP-Man NPs) retained their normal glycosylation pattern. The results in Fig. 10A, B and C, indicate the spots that were present in the control samples, that the deficient cells did not have spots, and the spots that reappeared following treatment, respectively. Furthermore, seven proteins present in the F3 fibroblasts were absent in the F3 (GDP-Man NPs) fibroblasts (Fig. 11A and B). These results suggest that the treatment may improve the post-translational protein glycosylation in vitro.

\section{Discussion}

Despite several attempts (35), no effective therapy has been developed to alleviate CDG-Ia symptoms. The present study aimed to demonstrate the efficacy of the administration of GDP-Man. The current hypothesis was that the introduction of GDP-Man to the cell restores the $\mathrm{N}$-glycosylation pathway so that branched oligosaccharide chains can be mounted on proteins. However, the addition of free GDP-Man in the medium exerted no effects on the activities of the enzymes examined. PLGA nanoparticles were used to deliver GDP-Man into deficient cells. It was possible to produce two batches, which exhibited optimal features, suggesting that GDP-Man is a molecule that can be loaded on PLGA NPs. 

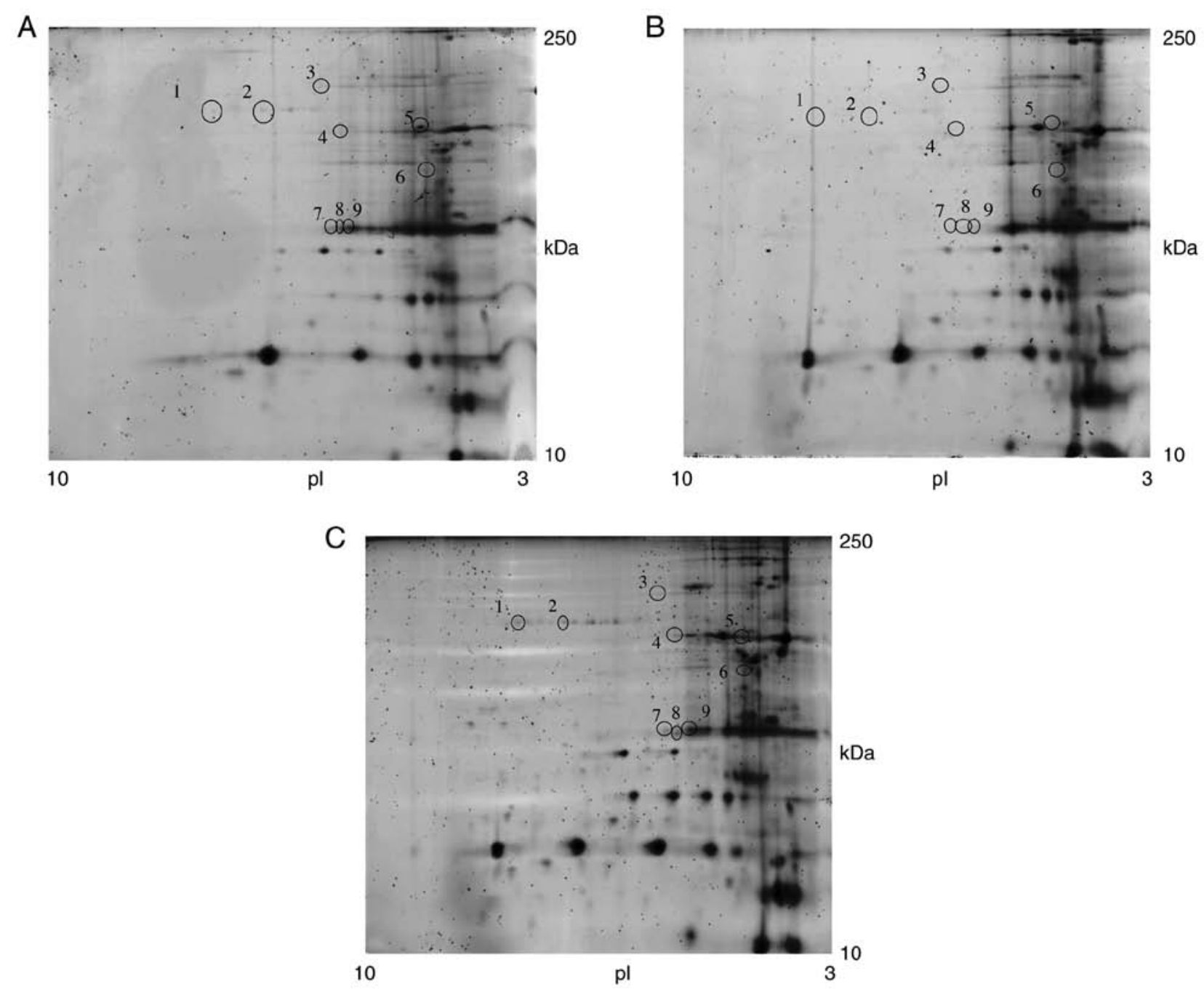

Figure 10. 2-DE map of glycoproteins. 2-DE map of glycoproteins from (A) HF, (B) CDG-Ia_F3 fibroblasts, and (C) F3_GDP-Man NPs treated for 6 h with GDP-Man PLGA NPs and analysed $48 \mathrm{~h}$ post-incubation. Immobilised $\mathrm{pH}$ gradient $\mathrm{pH}$ 3.0-10.0 non-linear strips were used for the first dimension and $12 \%$ polyacrylamide gels were used for the second dimension. The circles indicate the glycoproteins that were present in HF and were not present in CDG-Ia_F3. These glycoproteins were rescued following treatment with GDP-Man PLGA NPs. 2-DE, two-dimensional electrophoresis; HF, healthy fibroblasts; CDG-Ia, congenital disorder of glycosylation type Ia; GDP-Man, guanosine 5'-diphospho-D-mannose; PLGA, poly (D,L-lactide-co-glycolide); NPs, nanoparticles.
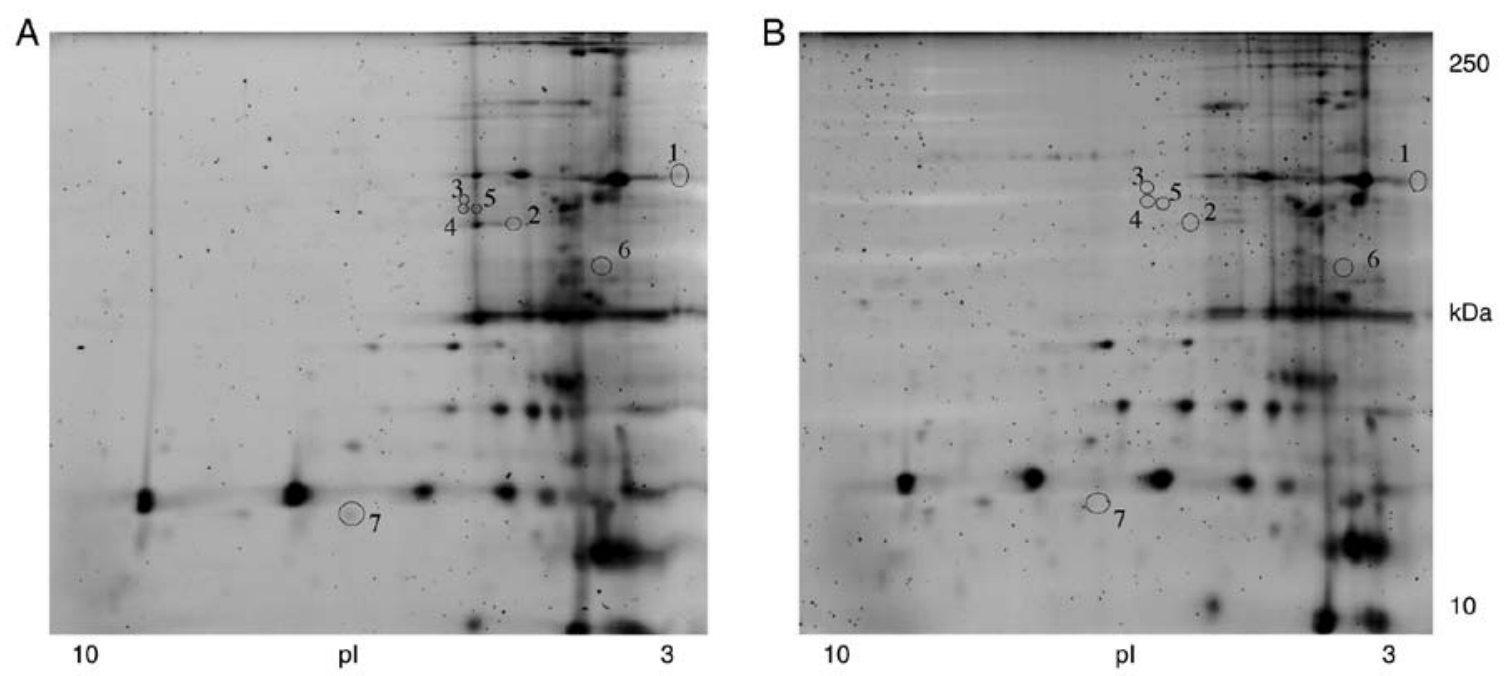

Figure 11. 2-DE map of glycoproteins. 2-DE map of glycoproteins from (A) CDG-Ia_F3 fibroblasts and (B) F3_GDP-Man NPs treated $6 \mathrm{~h}$ with GDP-Man PLGA NPs and analysed $48 \mathrm{~h}$ post-incubation. Immobilised $\mathrm{pH}$ gradient $\mathrm{pH}$ 3.0-10.0 non-linear strips were used for the first dimension and $12 \%$ polyacrylamide gels were used for the second dimension. The circles indicate glycoproteins that were present in CDG-Ia_F3 fibroblasts and were lost in F3_GDP-Man NPs. These glycoproteins were lost following treatment with GDP-Man PLGA NPs. 2-DE, two-dimensional electrophoresis; HF, healthy fibroblasts; CDG-Ia, congenital disorder of glycosylation type Ia; GDP-Man, guanosine 5'-diphospho-D-mannose; PLGA, poly (D,L-lactide-co-glycolide); NPs, nanoparticles. 
Fibroblasts were considered an optimal marker to assess the efficacy of the delivery method. This was achieved by measuring the activity of lysosomal enzymes. Lysosomal enzymes represent a class of proteins whose function mainly depends on oligosaccharide chains that are linked to asparagine amino groups. Assessment of the lysosomal enzymes allowed determination of the dose of administration, the incubation time and the time required for the successful delivery of GDP-Man. Of note, the most effective dose was $15 \mathrm{ng} /$ well, instead of $150 \mathrm{ng} /$ well, whereas the optimal incubation time was $6 \mathrm{~h}$. The production of lysosomal enzymes is a process that requires a long period of time, whereas the maximal specific activity was recorded $48 \mathrm{~h}$ following incubation.

Lysosomal enzymes, including $\alpha$-mannodisase and $\beta$-glucoronidase, were used as reference enzymes to determine glycosylation in vitro, as previous evidence has demonstrated that their activity was reduced significantly in CDG-Ia leukocytes (1). The in vitro results of the present study demonstrated that GDP-Man PLGA nanoparticles comprise a successful treatment for CDG-Ia with optimal efficacy. To date, low levels of glycosylation have been determined in fibroblast culture medium and in the serum of patients with xCDG-Ia.

Increases in the serum activity of the $\alpha$-fucosidase and $\beta$-hexosaminidase enzymes were also noted in these patients. The lack of GDP-Man impaired the processing of glycoproteins, and affected the cell metabolism.

CDG-Ia can cause neurological disorders. Therefore, PLGA nanoparticles are particularly useful due to their ability to cross the $\mathrm{BBB}$ when coated with a short glycopeptide that is linked to the endothelial $\mu$ opioid receptor $(\mathrm{g} 7)(15,16)$. Recently, Chan et al reported the generation of the first viable PMM2 hypomorphic mouse model, which recapitulates several features of the CDG-Ia disease (36). To the best of our knowledge, the present study is the first to describe successful in vitro treatment of a metabolic disorder using a nanoparticle-mediated therapeutic approach, which is based on the delivery of GDP-Man.

In conclusion, this model allows the assessment of glycosylation-targeted therapies, and these strategies may be used to treat CDG-Ia and other glycosylation genetic disorders with similar aetiology.

\section{Acknowledgements}

The authors would like to thank the 'Cell Line and DNA Biobank from Patients affected by Genetic Diseases' and the Centro di Diagnostica Genetica e Biochimica delle Malattie Metaboliche, Istituto G. Gaslini Genova for providing patient fibroblasts. The abstract was presented at the International Conference on Nanomedicine and Nanobiotechnology, Sep 28-Sep 302016 in Paris, France.

\section{Funding}

The present study was supported by a grant from the Institute for Maternal and Child Health IRCCS 'Burlo Garofolo' (grant no. RC 37/09). DME PhD fellowship was supported by Azzurra Malattie Rare ONLUS and the University of Trieste (grant no. 30/2013).

\section{Availability of data and materials}

All data generated or analyzed during this study are included in this published article.

\section{Authors' contributions}

BB was involved in the conception and design of the study, performed the majority of the cellular experiments and contributed to the drafting and revision of the article. EDM, SB and RA contributed to the experimental work, analysis, acquisition and interpretation of data regarding the biochemical experiments. AT contributed to the experimental work, analysis, acquisition and interpretation of data regarding the biochemical characterization of deficient fibroblasts. BU contributed to the experimental work, analysis, acquisition and interpretation of data regarding the 2-DE. BR contributed to the experimental work regarding the characterization of GDP-loaded NPs and contributed to the drafting and revision of the article. MA contributed to the experimental work, analysis, acquisition and interpretation of data regarding the genetic characterization of the deficient fibroblasts. GT contributed to the experimental work regarding the GDP-loaded NP preparation and characterization, and contributed to the production of the draft and revision of the article. DD was involved in the conception and design of the study, analysis and interpretation of the data, and made a fundamental scientific contribution to the production of the draft and the revision of the article. GMS coordinated the activities of all the groups, contributed to the conception and design of the study, analysis and interpretation of the data, and made a fundamental scientific contribution for the production of the draft and the revision of the article. All authors approved the submission of the present article.

\section{Ethics approval and consent to participate}

Approval was granted by the Human Subjects Protection Review Board of the Institute for Maternal and Child Health IRCCS 'Burlo Garofolo' (Technical Scientific Committee of the Scientific Directorate).

\section{Patient consent for publication}

Informed consent was provided by the parents or legal representatives of subjects involved.

\section{Competing interests}

The authors declare that they have no competing interests.

\section{References}

1. Barone R, Carchon H,Jansen E,Pavone L,Fiumara A,Bosshard NU, Gitzelmann R and Jaeken J: Lysosomal enzyme activities in serum and leukocytes from patients with carbohydrate-deficient glycoprotein syndrome type IA (phosphomannomutase deficiency). J Inherit Metab Dis 21: 167-172, 1998.

2. Jaeken J: Congenital disorders of glycosylation. Ann NY Acad Sci 1214: 190-198, 2010.

3. Ichisaka S, Ohno K, Yuasa I, Nanba E, Sakuraba H and Suzuki Y: Increased expression of beta-hexosaminidase alpha chain in cultured skin fibroblasts from patients with carbohydrate-deficient glycoprotein syndrome type I. Brain Dev 20: 302-306, 1998. 
4. Schwarze SR, Ho A, Vocero-Akbani A and Dowdy SF: In vivo protein transduction: Delivery of a biologically active protein into the mouse. Science 285: 1569-1572, 1999.

5. Elson-Schwab L, Garner OB, Schuksz M, Crawford BE, Esko JD and Tor Y: Guanidinylated neomycin delivers large, bioactive cargo into cells through a heparan sulfate-dependent pathway. J Biol Chem 282: 13585-13591, 2007.

6. Snyder EL and Dowdy SF: Cell penetrating peptides in drug delivery. Pharm Res 21: 389-393, 2004.

7. Freeze HH: Towards a therapy for phosphomannomutase 2 deficiency, the defect in CDG-Ia patients. Biochim Biophys Acta 1792: 835-840, 2009.

8. Eklund EA, Merbouh N, Ichikawa M, Nishikawa A, Clima JM, Dorman JA, Norberg T and Freeze HH: Hydrophobic Man-1-P derivatives correct abnormal glycosylation in type I congenital disorder of glycosylation fibroblasts. Glycobiology 15: 1084-1093, 2005.

9. Mayatepek E, Schröder M, Kohlmüller D, Bieger WP and Nützenadel W: Continuous mannose infusion in carbohydrate-deficient glycoprotein syndrome type I. Acta Paediatr 86: 1138-1140, 1997.

10. Kjaergaard S, Kristiansson B, Stibler H, Freeze HH, Schwartz M, Martinsson T and Skovby F: Failure of short-term mannose therapy of patients with carbohydrate-deficient glycoprotein syndrome type 1A. Acta Paediatr 87: 884-888, 1998.

11. Mayatepek E and Kohlmüller D: Mannose supplementation in carbohydrate-deficient glycoprotein syndrome type I and phosphomannomutase deficiency. Eur J Pediatr 157: 605-606, 1998.

12. Brasil S,PascoalC,Francisco R,Marques-da-Silva D, Andreotti G, Videira PA, Morava E, Jaeken J and Dos Reis Ferreira V: CDG therapies: From bench to bedside. Int J Mol Sci 19: E1304, 2018.

13. Parveen S, Misra R and Sahoo SK: Nanoparticles: A boon to drug delivery, therapeutics, diagnostics and imaging. Nanomedicine 8 : 147-166, 2012

14. Tancini B, Tosi G, Bortot B, Dolcetta D, Magini A, De Martino E, Urbanelli L, Ruozi B, Forni F, Emiliani C, et al: Use of polylactide-co-glycolide-nanoparticles for lysosomal delivery of a therapeutic enzyme in glycogenosis type II fibroblasts. J Nanosci Nanotechnol 15: 2657-2666, 2015.

15. Costantino L, Gandolfi F, Tosi G, Rivasi F, Vandelli MA and Forni F: Peptide-derivatized biodegradable nanoparticles able to cross the blood-brain barrier. J Control Release 108: 84-96, 2005.

16. Tosi G, Bortot B, Ruozi B, Dolcetta D, Vandelli MA, Forni F and Severini GM: Potential use of polymeric nanoparticles for drug delivery across the blood-brain barrier. Curr Med Chem 20 2212-2225, 2013.

17. Bondioli L, Costantino L, Ballestrazzi A, Lucchesi D, Boraschi D, Pellati F, Benvenuti S, Tosi G and Vandelli MA: PLGA nanoparticles surface decorated with the sialic acid, $\mathrm{N}$-acetylneuraminic acid. Biomaterials 31: 3395-3403, 2010.

18. Rosca ID, Watari F and Uo M: Microparticle formation and its mechanism in single and double emulsion solvent evaporation. J Control 99: 271-280, 2004.

19. Ruozi B, Belletti D, Forni F, Sharma A, Muresanu D, Mössler H, Vandelli MA, Tosi G and Sharma HS: Poly (D,L-lactide-co-glycolide) nanoparticles loaded with cerebrolysin display neuroprotective activity in a rat model of concussive head injury. CNS Neurol Disord Drug Targets 13: 1475-1482, 2014.

20. Joshi DP, Lan-Chun-Fung YL and Pritchard JG: Determination of poly(vinyl alcohol) via its complex with boric acid and iodine. Anal Chim Acta 104: 153-160, 1979.

21. Belletti D, Grabrucker AM, Pederzoli F, Menrah I, Vandelli MA, Tosi G, Duskey TJ, Forni F and Ruozi B: Hybrid nanoparticles as a new technological approach to enhance the delivery of cholesterol into the brain. Int J Pharm 543: 300-310, 2018
22. Pirard M, Achouri Y, Collet JF, Schollen E, Matthijs G and Van Schaftingen E: Kinetic properties and tissular distribution of mammalian phosphomannomutase isozymes. Biochem J 339: 201-207, 1999.

23. Barone R, Carrozzi M, Parini R, Battini R, Martinelli D, Elia M, Spada M, Lilliu F, Ciana G, Burlina A, et al: A nationwide survey of PMM2-CDG in Italy: High frequency of a mild neurological variant associated with the L32R mutation. J Neurol 262: 154-164, 2015

24. Vega AI, Pérez-Cerdá C, Abia D, Gámez A, Briones P, Artuch R, Desviat LR, Ugarte $M$ and Pérez B: Expression analysis revealing destabilizing mutations in phosphomannomutase 2 deficiency (PMM2-CDG): Expression analysis of PMM2-CDG mutations. J Inherit Metab Dis 34: 929-939, 2011.

25. Grünewald S, Schollen E, Van Schaftingen E, Jaeken J and Matthijs G: High residual activity of PMM2 in patients' fibroblasts: Possible pitfall in the diagnosis of CDG-Ia (phosphomannomutase deficiency). Am J Hum Genet 68: 347-354, 2001.

26. Bortot B, Cosentini D, Faletra F, Biffi S, De Martino E, Carrozzi $M$ and Severini GM: PMM2-CDG: Phenotype and genotype in four affected family members. Gene 531: 506-509, 2013.

27. Monaco I, Arena F, Biffi S, Locatelli E, Bortot B, La Cava F, Marini GM, Severini GM, Terreno E and Comes Franchini M: Synthesis of lipophilic core-shell $\mathrm{Fe}_{3} \mathrm{O}_{4} @ \mathrm{SiO}_{2} @$ Au nanoparticles and polymeric entrapment into nanomicelles: A novel nanosystem for in vivo active targeting and magnetic resonance-photoacoustic dual imaging. Bioconjug Chem 28: 1382-1390, 2017.

28. Carcoforo P, Ura B, Mischiati C, Squerzanti M, Lanzara V, Cervellati C, Calza R, De Laureto PP, Frare E, Portinari M, et al: Comparative proteomic analysis of ductal breast carcinoma demonstrates an altered expression of chaperonins and cytoskeletal proteins. Mol Med Rep 7: 1700-1704, 2013.

29. Sahay G, Alakhova DY and Kabanov AV: Endocytosis of nanomedicines. J Control Release 145: 182-195, 2010.

30. Hu Q, Gu G, Liu Z, Jiang M, Kang T, Miao D, Tu Y, Pang Z, Song Q, Yao L, et al: F3 peptide-functionalized PEG-PLA nanoparticles co-administrated with tLyp-1 peptide for anti-glioma drug delivery. Biomaterials 34: 1135-1145, 2013.

31. Rush JS, Panneerselvam K, Waechter CJ and Freeze HH Mannose supplementation corrects GDP-mannose deficiency in cultured fibroblasts from some patients with Congenital Disorders of Glycosylation (CDG). Glycobiology 10: 829-835, 2000.

32. Kleinert P, Kuster T, Arnold D, Jaeken J, Heizmann CW and Troxler H: Effect of glycosylation on the protein pattern in 2-D-gel electrophoresis. Proteomics 7: 15-22, 2007.

33. Cartiera MS, Johnson KM, Rajendran V, Caplan MJ and Saltzman WM: The uptake and intracellular fate of PLGA nanoparticles in epithelial cells. Biomaterials 30: 2790-2798, 2009.

34. Livak KJ and Schmittgen TD: Analysis of relative gene expression data using real-time quantitative PCR and the 2(-Delta Delta C(T)) method. Methods 25: 402-408, 2001.

35. Van Scherpenzeel M, Willems E and Lefeber DJ: Clinical diagnostics and therapy monitoring in the congenital disorders of glycosylation. Glycoconj J 33: 345-358, 2016.

36. Chan B, Clasquin M, Smolen GA, Histen G, Powe J, Chen Y, Lin Z, Lu C, Liu Y, Cang Y, et al: A mouse model of a human congenital disorder of glycosylation caused by loss of PMM2. Hum Mol Genet 25: 2182-2193, 2016. 